\title{
Metaplasia Óssea e Esterilidade Primária
}

\author{
Endometrial Osseous Metaplasia and Primary Infertility
}

Celeste P. Demeterco Reggiani, Marcelo K. Murata, Marcelo G. Cequinel, César A. Cornel Jorjan Cruz, Jean F. Francisco, Augusto F. Beduschi

\begin{abstract}
RESUM0
A metaplasia óssea do endométrio é uma condição rara e pode ser explicada por uma neoformação no endométrio, com deposição de sais de cálcio. Entretanto, a situação mais comum é a história prévia de abortamento com permanência de ossiculos na cavidade uterina. Foi relatado um caso de ossificação endometrial em uma mulher de 31 anos, sem gravidez prévia ou história de aborto, apresentando dismenorréia e infertilidade. A ultra-sonografia pélvica mostrou área hiperecóica no fundo da cavidade uterina. A histeroscopia foi realizada e uma imagem sugestiva de tecido ósseo foi encontrada. Este tecido foi retirado e a histopatologia confirmou a ossificação endometrial.
\end{abstract}

PALAVRAS-CHAVE: Ossificação endometrial. Metaplasia óssea. Infertilidade.

\section{Introdução}

A metaplasia óssea do endométrio é uma condição rara, de etiologia controversa. Ainda que possa ser explicada como uma osteogênese das camadas profundas do endométrio, com deposição de sais de cálcio, a situação mais comum para seu aparecimento é a história prévia de abortamento com retenção de ossículos na cavidade uterina $^{1}$. A maioria das pacientes estão entre 20 e 40 anos e os fatores mais comuns são as endometrites e os abortos recorrentes ${ }^{2}$. A apresentação clínica inclui infertilidade primária ou secundária, sangramento vaginal anormal, dor pélvica e dispareunia ${ }^{2-4}$. O diagnóstico desta patologia é feito por meio de histeroscopia, que mostra tecido ósseo na cavidade uterina, associada à biópsia ${ }^{5}$. Em nosso estudo relatamos um caso de metaplasia óssea do endométrio com infertilidade primária.

\section{Relato do caso}

A paciente TAG, 31 anos, nuligesta, foi en-

Faculdade Evangélica de Medicina do Paraná

Hospital Universitário Evangélico de Curitiba

Departamento de Tocoginecologia

Correspondência:

Celeste Pauline Demeterco Reggiani

Rua: Santa Clara, 437.

82200-380 - Curitiba - PR

Fone/fax: (41) 253-2382 caminhada ao ambulatório de ginecologia de um hospital de Curitiba com laudo ecográfico, datado de 29/10/97, sugestivo de metaplasia óssea na cavidade uterina. Na história mórbida pregressa, referia dor pélvica, dispareunia e história de 4 anos de infertilidade primária. Seus antecedentes pessoais e familiares não eram relevantes.

No que se refere à história ginecológica, após sua menarca aos 12 anos, a paciente teve ciclos menstruais regulares de 30-30 dias e fluxo com 5 dias de duração. Relatou início das atividades sexuais aos 20 anos, sem nunca ter usado nenhum método anticoncepcional. Ainda, relatava dismenorréia e tensão pré-menstrual.

Entre os exames laboratoriais apresentados a dosagem hormonal estava dentro dos padrões de normalidade. O cônjuge apresentou espermograma sem alterações.

Histerossalpingografia, datada de 12 de janeiro de 1998, mostrava cavidade uterina de contorno pouco irregular e pequena falha de enchimento corporal sugestiva de sinéquia (Figura 1). As trompas eram permeáveis e não mostravam nenhuma alteração radiográfica.

Em 4 de fevereiro de 1998 foi realizada nova ecografia pélvica, que mostrou calcificações no endométrio, com imagem hiperecóica sugestiva de corpo estranho no fundo uterino (Figura 2). Realizada uma histeroscopia em maio desse mesmo ano, revelou-se uma imagem de tecido ósseo na cavidade uterina parcialmente inserido no endométrio. Macroscopicamente, observaram-se múltiplos fragmentos irregulares de tecido 
esbranquiçado recebidos de permeio com coágulos sangüíneos e tecido róseo mole (Figura 3).

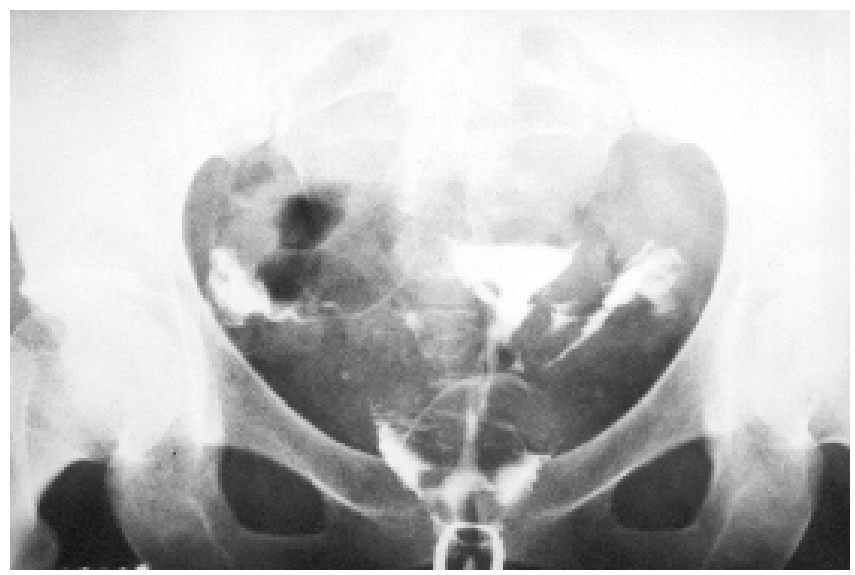

Figura 1 - Histerossalpingografia: cavidade uterina de contorno pouco irregular e pequena falha de enchimento corporal sugestiva de sinéquia. Trompas permeáveis e sem alteração radiográfica.

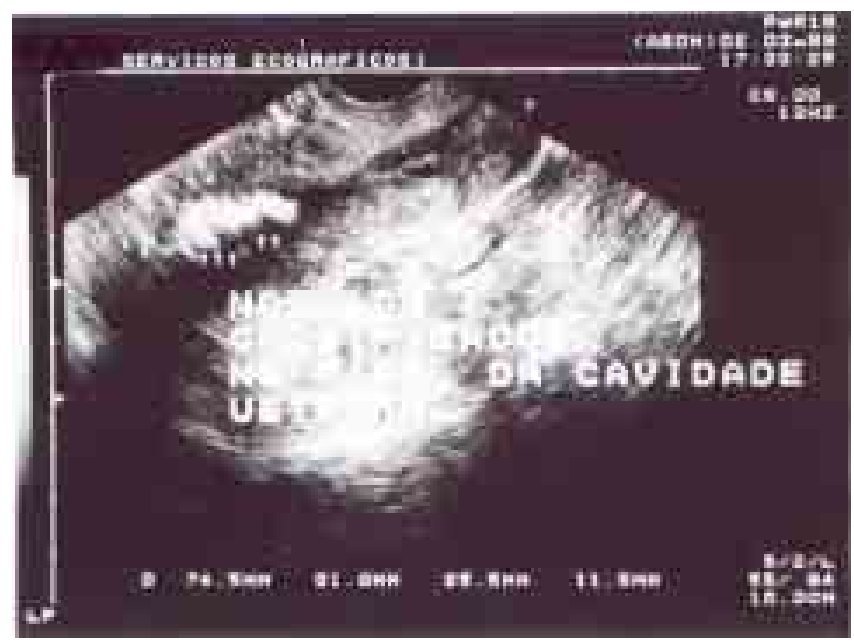

Figura 2 - Ecografia pélvica: calcificações no endométrio, com imagem hiperecóica sugestiva de corpo estranho no fundo uterino.

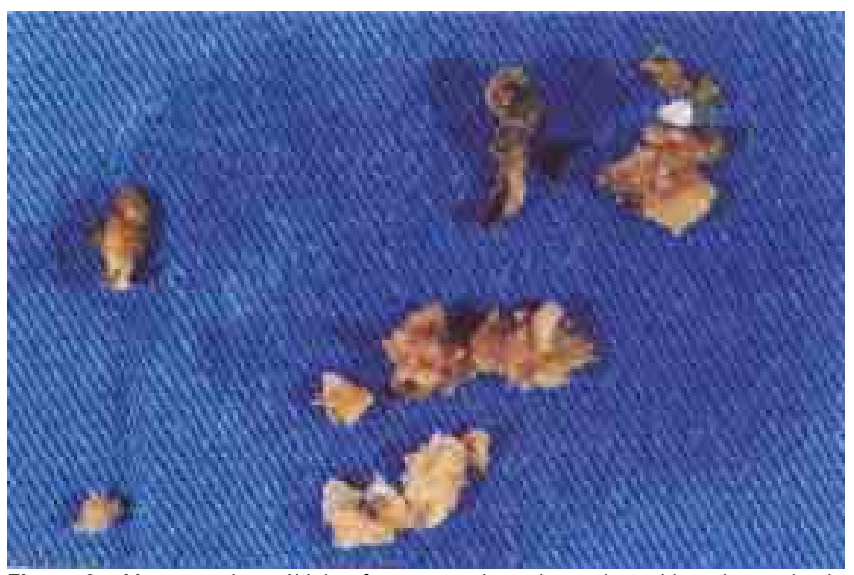

Figura 3 - Macroscopia: múltiplos fragmentos irregulares de tecido esbranquiçado recebidos de permeio com coágulos sangüíneos e tecido róseo mole.
A análise histopatológica mostrou endométrio em fase de secreção com coágulos sangüineos em organização e focos de metaplasia óssea.

\section{Discussão}

Este tipo de patologia endometrial é rara e, na maioria dos casos relatados, a etiologia é controversa. Três teorias quanto às possiveis etiologias da ossificação endometrial foram propostas ao decorrer dos anos. Thaler ${ }^{6}$ sugeriu a teoria da calcificação e ossificação por retenção de tecido fetal pós-aborto. De acordo com esta teoria, a gestação deve durar pelo menos 3 meses, com o feto já em estágio de ossificação endocondral ${ }^{6}$. Neuman ${ }^{7}$ sugeriu a segunda teoria, que propõe a presença de células mesenquimais multipotenciais no útero, que seriam responsáveis pela formação de tecido ectópico neste local. A terceira teoria, proposta por von Gierke ${ }^{8}$, considera que endometrites crônicas, tuberculose, excesso de vitamina $\mathrm{D}$ e uso prolongado de estrogênio podem ser responsáveis pelo estímulo da metaplasia de células estromais do endométrio em cartilagem ou tecido ósseo fetal.

Em nosso caso, a ocorrência de metaplasia pareceu ser a melhor explicação, tendo em vista que a paciente não tinha história de gestação, aborto prévio ou endometrite crônica. Esta possibilidade concorda com o caso relatado por Ombelet ${ }^{9}$. Entretanto, a maioria dos autores descreve casos de ossificação endometrial decorrentes de retenção de tecido ósseo ou cartilagem fetal pósabortamento $^{1-5}$.

Em relação à avaliação da infertilidade feminina, os fatores endometriais locais são pouco considerados. Endometrite crônica, aderência intra-uterina e mioma submucoso são responsabilizados mais comumente. A infertilidade secundária está relacionada com a maioria dos casos relatados, como mostram os estudos de Marcus et al. ${ }^{1}$, Torné et al. ${ }^{4}$, Rodriguez e Adamson ${ }^{3}$ e Acharya et al. ${ }^{5}$. Casos de infertilidade primária, ao contrário, são extremamente raros. Ombelet ${ }^{9}$ relatou um caso de uma paciente com história de infertilidade primária por sete anos em que, durante uma laparoscopia diagnóstica com biópsia, foram encontradas estruturas ósseas no fundo uterino.

Quanto à clínica desta patologia, todos os autores referem a possibilidade de sangramento anormal, dor pélvica, e infertilidade ${ }^{1-5,9}$. No caso da nossa paciente, dor pélvica, dispareunia e infertilidade primária estavam presentes.

A investigação diagnóstica do caso relatado 
neste trabalho concorda com aquela realizada nos dois casos descritos por Marcus et al. (1994) ${ }^{1}$ e na paciente com infertilidade primária estudada por Ombelet ${ }^{9}$. Inicialmente, fez-se ecografia pélvica com laudo sugestivo de metaplasia óssea. Posteriormente, para a confirmação do diagnóstico, realizou-se histeroscopia, que mostrou tecido ósseo na cavidade uterina. O diagnóstico definitivo veio com a biópsia deste tecido: metaplasia óssea de endométrio ${ }^{1,9}$.

Concluiu-se neste trabalho que a possibilidade de ossificação endometrial deve também ser considerada em pacientes inférteis, independentemente da existência de gestação prévia, principalmente quando o diagnóstico é suspeitado por ecografia pélvica. Para confirmar esta hipótese, o melhor procedimento é a realização de histeroscopia com biópsia e análise histopatológica.

\section{SUMMARY}

Endometrial metaplastic ossification is a rare condition and can be partially explained by a neoformation in the endometrium, with calcium deposition. However, a common situation is the previous history of abortion with persistence of ossicles in the uterine cavity. The endometrial ossification was reported in a 31-year-old woman, without previous pregnancy or history of abortion. This patient presented dysmenorrhea and infertility. Pelvic ultrasonography showed a hyperechoic area in the uterine fundus. Histeroscopy was performed and an image suggestive of bone was seen. This tissue was removed by histeroscopy and the histopathological analysis confirmed endometrial ossification.

KEY WORDS: Endometrial ossification. Osseous metaplasia. Infertility.

\section{Referências}

1. Marcus SF, Bhattacharya J, Williams G, Brinsden P, Hamou J. Endometrial ossification: a cause of secondary infertility. Report of two cases. Am J Obstet Gynecol 1994; 170:1381-3.

2. Shimizu M, Nakayama M. Endometrial ossification in a postmenopausal woman. J Clin Pathol 1997; 50:171-2.

3. Rodriguez BD, Adamson GD. Hysteroscopic treatment of ectopic intrauterine bone: a case report. J Reprod Med 1993; 38:515-20.

4. Torné A, Jou P, Pagano R, Sanchez I, Ordi J, Vanrell JA. Endometrial ossification successfully treated by hysteroscopic resection. Eur J Obstet Gynecol Reprod Biol 1996; 66:75-7.

5. Acharya U, Pinion SB, Parkin DE, Hamilton MP. Osseous metaplasia of the endometrium treated by hysteroscopic resection. Br J Obstet Gynaecol 1993; 100:391-2.

6. Thaler H. Überlebendes fötales Knorpelgewebe in der Uterushöhle nach Abortus. Z Gynaekol 1923; 46/47:1784-6.

7. Neuman HO. Eine Knorpelinsel im fundus uteri. Arch Gynaekol 1925; 126:1-10.

8. von Gierke E. Über Knorpelinseln in Uterusausschabungen. Zentralbl Allg Pathol Pathol Anat 1935; 62:145-9.

9. Ombelet W. Endometrial ossification, an unusual finding in an infertility clinic: a case report. J Reprod Med 1989; 34:303-6. 